\title{
Parthenogenetic activation of bovine oocytes using single and combined strontium, ionomycin and 6-dimethylaminopurine treatments
}

\author{
S.C. Méo ${ }^{1,2}$, W. Yamazaki ${ }^{2}$, C.R. Ferreira ${ }^{2}$, F. Perecin $^{2}$, N.Z. Saraiva ${ }^{2}$, \\ C.L.V. Leal ${ }^{3}$ and J.M. Garcia ${ }^{2}$ \\ Centro de Genética e Reprodução Animal, Instituto de Zootecnia Nova Odessa; Departamento de Medicina Veterinária \\ Preventiva e Reprodução Animal, FCAV - UNESP, Jaboticabal; and Departamento de Ciências Básicas, FZEA - USP, \\ Pirassununga, SP, Brazil
}

Date submitted: 04.12.06. Date accepted: 29.01.07

\section{Summary}

In vitro-matured (IVM) bovine oocytes were activated with single and combined treatments of strontium (S), ionomycin (I) and 6-DMAP (D). Using oocytes IVM for $26 \mathrm{~h}$, we observed that activation altered cell cycle kinetics (faster progression, MIII arrest, or direct transition from MII to pronuclear stage) when compared to in vitro fertilization. The effect of oocyte age on early parthenogenesis was assessed in oocytes IVM for 22, 26 and $30 \mathrm{~h}$. Better results in pronuclear development were obtained in treatments ISD $(81.7 \%)$ at $22 \mathrm{~h} ; \mathrm{D}(66.7 \%)$, IS (63.3\%), ID (73.3\%) and ISD (76.7\%) at $26 \mathrm{~h}$; and D (86.7\%), IS (85.0\%) and ID $(78.3 \%)$ at $30 \mathrm{~h}$. Higher cleavage occurred on ISD (80.0\%) at $22 \mathrm{~h}$; ID (83.3\%) and ISD (91.7\%) at $26 \mathrm{~h}$; and I (86.7\%), IS (90.0\%), ID (85.0\%) and ISD (95.0\%) at $30 \mathrm{~h}$. More blastocysts were achieved in ID $(25.0 \%)$ and ISD (18.3\%) at $22 \mathrm{~h}$; and in ID at $26 \mathrm{~h}(45.0 \%)$ and $30 \mathrm{~h}(50.0 \%)$. We also observed that IS allowed higher haploid (77.4\%) embryonic development, whilst ID was better for diploid (89.1\%) development. It was concluded that association of S and D without I was not effective for blastocyst development; treatments using $S$ were less influenced by oocyte age, but when $S$ was associated with $D$ there was a detrimental effect on aged oocytes; treatment ISD promoted higher activation and cleavage rates in young oocytes and ID protocol was the best for producing blastocysts.

Keywords: Cattle, Chromatin, Embryonic development, Microtubules, Oocyte activation

\section{Introduction}

Study and improvement of artificial activation techniques are required in several embryo biotechnologies. Activation is a key step for procedures such as

All correspondence to: S.C. Méo, Embrapa Pecuária Sudeste, Rodovia Washington Luiz, km 234, CEP 13560-970, São Carlos, SP, Brazil. Tel: +55 163361 5611. Fax: +55 163361 5754. e-mail: simone@cppse.embrapa.br

${ }^{1}$ Centro de Genética e Reprodução Animal, Instituto de Zootecnia, Rua Heitor Penteado, 56, 13460-000, Nova Odessa, SP, Brazil.

${ }^{2}$ Departamento de Medicina Veterinária Preventiva e Reprodução Animal, FCAV - UNESP, Via de Acesso Prof. Paulo Donato Castellane, s/n, 14884-900, Jaboticabal, SP, Brazil.

${ }^{3}$ Departamento de Ciências Básicas, FZEA - USP, Avenida Duque de Caxias Norte, 225, 13635-900, Pirassununga, SP, Brazil. somatic cell nuclear transfer (SCNT; Wells et al., 1999), intracytoplasmic sperm injection (ICSI; Suttner et al., 2000) and round-spermatid injection (ROSI; Loren \& Lacham-Kaplan, 2006). Furthermore, activation is used for elucidation of events during early embryonic development (Soloy et al., 1997) and for studies on genomic imprinting (Solter, 1988).

Ovulated or in vitro-matured bovine oocytes are arrested in metaphase II (MII) until activation by spermatozoa or by an artificial stimulus. This cell cycle arrest occurs mainly due to the persistence of high activity of maturation promoting factor (MPF) and mitogen-activated protein (MAP) kinases (Dupont, 1998). When a spermatozoon activates an oocyte, it promotes multiple and periodic oscillations of intracellular free calcium $\left(\left[\mathrm{Ca}^{2+}\right]_{i}\right.$; Yang et al., 1994), which are mediated by receptors and second messengers after membrane interaction between gametes and by 
the release of a soluble sperm factor (Malcuit et al., 2006). Oscillations on $\left[\mathrm{Ca}^{2+}\right]_{i}$ are necessary for meiosis resumption, pronuclear formation, mitotic cleavage and embryo development (Küpker et al., 1998).

An artificial activation treatment is considered efficient when it achieves all physiological steps of activation. This can be more easily obtained by the use of aged oocytes (Kikuchi et al., 1995), by the promotion of multiple intracellular calcium pulses (Vitullo \& Ozil, 1992), or by the combination of different activation treatments (Yang et al., 1994; Liu et al., 1998). Activation agents act in distinct pathways, some provoke $\left[\mathrm{Ca}^{2+}\right]_{i}$ increase in one pulse, e.g. ionomycin and ethanol (Loi et al., 1998), or in multiple pulses, e.g. strontium (Cuthbertson et al., 1981), while others promote inhibition of protein synthesis, e.g. cycloheximide (Nussbaum \& Prather, 1995), or protein phosphorylation, e.g. 6-DMAP (Susko-Parrish et al., 1994). Since artificial treatments are not able to mimic all events promoted by the sperm cell (Nakada \& Mizuno, 1998) and obtaining efficiently activated young oocytes constitutes one of the limiting steps for the success of SCNT (Kishikawa et al., 1999), better comprehension of activation dynamics may benefit several technologies.

In our previous works, activation potential of strontium was evaluated in bovine oocytes (Méo et al., 2004). Strontium showed similar pronuclear, cleavage and blastocyst development rates compared to ethanol, but it increased total cell number in blastocysts (Méo et al., 2004). However, neither strontium and ethanol individually, nor the association of both were efficient to produce parthenogenetic blastocysts. Afterwards, aiming to improve activation and blastocyst development, we evaluated the influence of $\mathrm{Ca}^{2+}$ and $\mathrm{Mg}^{2+}$ in activation medium and tested several strontium concentrations and periods of incubation. The optimal strontium protocol achieved for bovine oocyte activation was $20 \mathrm{mM} \mathrm{SrCl}_{2}$ for $6 \mathrm{~h}$ in $\mathrm{Ca}^{2+}$ - and $\mathrm{Mg}^{2+}$-free TALP (Méo et al., 2005). This protocol was also employed to produce a live calf by SCNT (Yamazaki et al., 2005).

We observed that strontium treatment was less influenced by oocyte age and that the combination of strontium and ionomycin did not improve developmental rates (Méo et al., 2005). Then, since 6-DMAP is an unspecific phosphorylation inhibitor (Loi et al., 1998) that is broadly used for activation, while strontium is considered an artificial treatment more similar to fertilization (Bos-Mikich et al., 1995), in the present study, we evaluated single and associated strontium, ionomycin and 6-DMAP treatments to activate oocytes in three maturational ages. During early events of embryonic development, activated zygotes were compared to in vitro fertilized ones. Activation treatments were also assessed for pronuclear development and status, cleavage and blastocyst development and quality. The objectives were: (1) to compare nuclear dynamics in activated and fertilized oocytes; (2) to verify the possibilities of combining strontium and 6-DMAP; (3) to develop an artificial treatment not influenced by oocyte age in a great extent; and (4) to establish a reliable treatment for further application in different experimental designs involving artificial activation.

\section{Materials and methods}

Chemicals and media were purchased from Sigma Chemical Co., unless otherwise stated. Incubator conditions for oocytes and embryos during all experimentation were at $38.8^{\circ} \mathrm{C}$ under $5 \% \mathrm{CO}_{2}$ in air and maximum humidity.

\section{Oocyte recovery and in vitro maturation (IVM)}

Abattoir-derived ovaries were transported to the laboratory in saline solution at $28-32{ }^{\circ} \mathrm{C}$ and follicles from $3-7 \mathrm{~mm}$ of diameter were aspirated using an 18 -gauge needle attached to a $20 \mathrm{ml}$ syringe. Oocytes with at least four layers of cumulus cells were selected. The oocytes were matured in tissue culture medium (TCM-199, GIBCO BRL) supplemented with 10\% heatinactivated $\left(55^{\circ} \mathrm{C}\right.$ for $\left.30 \mathrm{~min}\right)$ fetal calf serum (FCS), $0.5 \mu \mathrm{g} / \mathrm{ml} \mathrm{FSH}$ (Folltropin; Bioniche Animal Health), $100 \mathrm{IU} / \mathrm{ml} \mathrm{hCG}$ (Profasi, Serono), $1.0 \mu \mathrm{g} / \mathrm{ml}$ estradiol, $0.25 \mathrm{mM}$ sodium pyruvate and $75 \mu \mathrm{g} / \mathrm{ml}$ kanamycin (GIBCO). IVM was performed in $100 \mu \mathrm{l}$ droplets with 10-20 oocytes/per drop under mineral oil (Dow Corning Co.) for 22 to $30 \mathrm{~h}$.

\section{Activation treatments}

After IVM for $20 \mathrm{~h}$, oocytes were stripped from cumulus cells with $0.2 \%$ hyaluronidase in calcium-free PBS with $0.1 \%$ polyvinyl alcohol for $5 \mathrm{~min}$ and then gentle pipetting for 3 to $5 \mathrm{~min}$. Oocytes with homogeneous cytoplasm and an extruded first polar body (1PB) were selected and remained in maturation droplets until activation procedures at 22,26 or $30 \mathrm{~h}$. The oocytes were washed three times in HEPES-buffered TCM199 (H199) with $3 \mathrm{mg} / \mathrm{ml}$ BSA (fraction V, fatty acid free; Inlab) before and immediately after the activation treatment.

Oocytes were randomly allocated and cultured in one of the following groups: (1) control (C): culture in synthetic oviductal fluid (SOF) supplemented with $2.5 \%$ FCS and $5 \mathrm{mg} / \mathrm{ml} \mathrm{BSA} \mathrm{in} \mathrm{the} \mathrm{absence} \mathrm{of}$ any activating agent; (2) strontium (S): culture in $20 \mathrm{mM} \mathrm{SrCl}_{2}$ in $\mathrm{Ca}^{2+}$ - and $\mathrm{Mg}^{2+}$-free TALP for $6 \mathrm{~h}$; (3) ionomycin (I): culture in $5 \mu \mathrm{M}$ ionomycin in H199 
(1 $\mathrm{mg} / \mathrm{ml} \mathrm{BSA}$ ) for $5 \mathrm{~min}$ at room temperature and further wash in H199 (30 mg/ml BSA) for $5 \mathrm{~min}$; (4) 6-DMAP (D): culture in $2 \mathrm{mM}$ 6-dimethylaminopurine for $4 \mathrm{~h}$ in $\mathrm{Ca}^{2+}$ - and $\mathrm{Mg}^{2+}$-free TALP with osmolarity corrected to 280-290 mOsm; (5) ionomycin + strontium (IS): oocytes submitted to treatment I, as described above, followed immediately by treatment $S$; (6) ionomycin + 6-DMAP (ID): oocytes submitted to treatment I, followed immediately by treatment $\mathrm{D}$; (7) ionomycin + strontium + 6-DMAP (ISD): oocytes submitted to treatment I, followed by treatments $S$ and $\mathrm{D}$; and (8) strontium + 6-DMAP (SD): oocytes submitted to treatments $S$ and D. For ISD and SD, the treatments $S$ and $D$ were handled in the following manner: treatment $S$ alone for $2 \mathrm{~h}$, then combined to treatment D for $4 \mathrm{~h}$, meaning a total of $6 \mathrm{~h}$ for $\mathrm{S}$ and $4 \mathrm{~h}$ for D. In ISD and SD treatments, since cultures in strontium and 6-DMAP were simultaneously performed, the medium of choice was the $\mathrm{Ca}^{2+}$ - and $\mathrm{Mg}^{2+}$-free TALP previously optimized for strontium (Méo et al., 2005). All treatments were replicated two times for immunofluorescence evaluation of tubulin and chromatin and five times for pronuclear development, cleavage and blastocyst development assessment.

\section{In vitro fertilization (IVF)}

In vitro fertilization was performed $24 \mathrm{~h}$ after IVM. Frozen semen was thawed in a $35^{\circ} \mathrm{C}$ water bath for $30 \mathrm{~s}$. The semen was separated by centrifugation in Percoll (Amersham Pharmacia Biotech) gradient (45 and $90 \%$ ) at $900 \mathrm{~g}$ for $30 \mathrm{~min}$. The obtained pellet, evaluated for concentration and sperm motility, was diluted in TALP with $10 \mu \mathrm{g} / \mathrm{ml}$ heparin and PHE $(18 \mu \mathrm{M}$ penicillamine, $10 \mu \mathrm{M}$ hypotaurine and $1.8 \mu \mathrm{M}$ epinephrine) and inseminated at a final concentration of $1 \times 10^{6}$ viable sperm $/ \mathrm{ml}$. The sperm was coincubated with IVM oocytes in $100 \mu$ l droplets of TALP under mineral oil. The zygotes obtained by IVF were used as control (IVF-Control) of the activated oocytes assessed for nuclear and microtubular dynamics by immunofluorescent evaluation of tubulin and chromatin.

\section{In vitro culture}

At the end of the activation treatment, oocytes were transferred to droplets $(100 \mu \mathrm{l})$ of SOF and cultured under mineral oil until activation assessment. Oocytes activated in the absence of 6-DMAP and designed for cleavage and blastocyst development were incubated in SOF supplemented with cytochalasin B $(10 \mu \mathrm{g} / \mathrm{ml})$ for $6 \mathrm{~h}$ in treatments C, I (immediately after the treatment with ionomycin), S and IS (simultaneously to the incubation with strontium). Cytochalasin was used to avoid second polar body (2PB) emission and to promote diploid embryonic development. Next, embryos were transferred to cytochalasin-free SOF.

\section{Immunofluorescent evaluation of tubulin and chromatin}

Oocytes fertilized after $24 \mathrm{~h}$ IVM were compared with oocytes activated after $26 \mathrm{~h}$ IVM. Since activation takes place immediately after the chemical treatment while the spermatozoon took about $4 \mathrm{~h}$ postinsemination (h.p.i.) to penetrate the oocyte (data not shown), we standardized $0 \mathrm{~h}$ as the onset of activation (e.g. the beginning of artificial treatment or 4 h.p.i.). The protocol used was described by Liu et al. (1998). Briefly, oocytes were incubated for $30 \mathrm{~min}$ in microtubule-stabilizing buffer (0.1M PIPES, pH 6.9; $5 \mathrm{mM} \mathrm{MgCl}_{2} \cdot 6 \mathrm{H}_{2} \mathrm{O}$ (Merck); $2.5 \mathrm{mM}$ EGTA) containing $2 \%$ paraformaldehyde, $0.1 \%$ Triton $\mathrm{X}-100,1 \mu \mathrm{M}$ taxol, $0.01 \%$ aprotinin, $1 \mathrm{mM}$ dithiothreitol and $50 \%$ deuterium oxide (Aldrich Chem. Co.). Afterwards, oocytes were blocked overnight in wash medium (WM; $0.02 \% \mathrm{NaN}_{3}$, 0.01\% Triton X-100, 0.2\% non-fat dry milk, 2\% FCS, 2\% BSA and $0.1 \mathrm{M}$ glycine in PBS) and then incubated with FITC-conjugated $\alpha$-tubulin mouse monoclonal antibody diluted to 1:50 in WM for $2 \mathrm{~h}$. After passage in WM, oocytes were stained for nuclear DNA visualization with $10 \mu \mathrm{g} / \mathrm{ml}$ Hoechst 33342 in WM for $10 \mathrm{~min}$, mounted on slides with $90 \%$ glycerol in PBS and observed under an epifluorescence microscope (330-385 $\mathrm{nm}$ and 420-490 nm). Oocytes were classified as metaphase II (MII), transition $\mathrm{MII} /$ pronucleus (MII/PN), metaphase III (MIII), anaphase or telophase $\mathrm{II}(\mathrm{A} / \mathrm{T})$ and pronuclear $(\mathrm{PN})$ stages.

\section{Pronuclear development and status, cleavage and blastocyst development and quality}

After 15 to $16 \mathrm{~h}$ of the activation treatment, oocytes were stained with $10 \mu \mathrm{g} / \mathrm{ml}$ Hoechst 33342 in H199 for $10 \mathrm{~min}$, visualized under an epifluorescence microscope (330-385 nm) and assessed for nuclear progression. Oocytes harbouring pronucleus were considered activated.

In pronuclear zygotes obtained from activated oocytes previously IVM for $26 \mathrm{~h}$, the number of pronuclei (PN) and polar bodies (PB) was also observed. Despite the initial equivalent number of oocytes in each treatment, pronuclear development rates were different, causing variation on the number of zygotes assessed for pronuclear status.

Cleavage was assessed 46 to $48 \mathrm{~h}$ after activation treatments under a stereoscopic microscope and 2- and 4-cell embryos were considered cleaved.

Blastocyst development rates and blastocyst quality were observed on day 7 after activation. The proportion of oocytes that achieved the blastocyst stage was determined. 

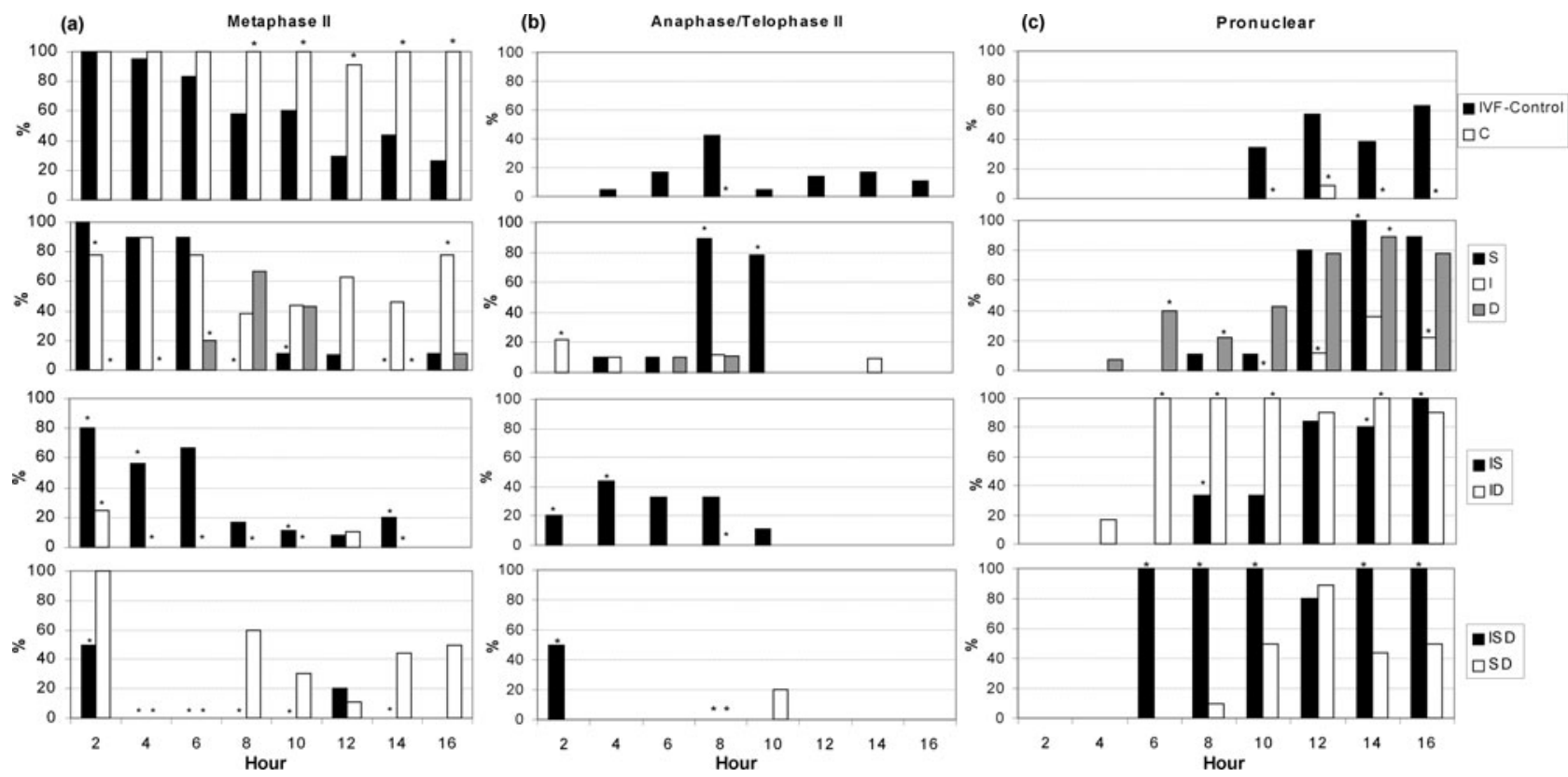

Figure 1 Normal progression of bovine metaphase II (a) oocytes through anaphase/telophase II $(b)$ and pronuclear $(c)$ stages from 2 to $16 \mathrm{~h}$ after the onset of fertilization (IVF-Control) or artificial activation: control group (C); $20 \mathrm{mM}$ strontium for $6 \mathrm{~h}$ (S); $5 \mu \mathrm{M}$ ionomycin for $5 \mathrm{~min}$ (I); $2 \mathrm{mM}$ 6-DMAP for $4 \mathrm{~h}$ (D); treatment I followed by treatment S (IS); treatments I and D (ID); treatments I, S and D (ISD); and treatments S and D (SD). Asterisk $(*)$ indicates significantly different $(p<0.05)$ from IVF-Control.

Differential staining of inner cell mass (ICM) and trophectoderm (TE) cells of expanded blastocysts (BosMikich et al., 1997) was used to evaluate embryo quality. Zona pellucida of expanded blastocysts was removed by incubation in $0.5 \%$ pronase in PBS for $1-1.5 \mathrm{~min}$. After washing three times in H199 supplemented with $10 \%$ FCS and once in H199, embryos were incubated in $10 \mathrm{mM}$ picric acid (Reagen, Quimibras Industrias) and $3 \mathrm{mg} / \mathrm{ml}$ PVP in PBS for $10 \mathrm{~min}$ over ice. Then, embryos were washed in $\mathrm{H} 199$ and exposed for $40 \mathrm{~min}$ to heat-inactivated rabbit anti-bovine spleen cell antiserum diluted 1:5 in H199. Later, embryos were washed in $\mathrm{H} 199+10 \%$ FCS and transferred to a 1:5 dilution of guinea pig complement in H199 containing $10 \mu \mathrm{g} / \mathrm{ml}$ propidium iodide and $10 \mu \mathrm{g} / \mathrm{ml}$ Hoechst 33342 for $40 \mathrm{~min}$. Labelled blastocysts were washed in PBS with $0.3 \%$ BSA, mounted on slides with glycerol and examined by epifluorescence microscopy (330-385 nm). Blue and red colours were designated as ICM and TE cells, respectively. Mean $( \pm S D)$ total, ICM and TE cell number in blastocysts and ICM/total cell ratio were determined. Since the number of treated oocytes was similar, but blastocyst rates were different among activation treatments, the number of embryos used to assess blastocyst quality was not uniform.

\section{Statistical analysis}

The proportion of activated oocytes for each treatment was analyzed by chi-squared analysis and, when appropriate, by Fisher's exact test. A level of 5\% significance was used.

\section{Results}

\section{Immunofluorescent evaluation of tubulin} and chromatin

Nuclear and microtubular patterns seen after fertilization or artificial activation were metaphase II (MII), anaphase or telophase II (A/T) and pronuclear (PN) stages. Unusual patterns such as transition $\mathrm{MII} /$ pronucleus (MII/PN) and metaphase III (MIII) stages were also observed.

Nuclear and microtubular dynamics are graphically represented in Figs. 1 and 2. In Fig. 1a, the percentage of oocytes arrested in MII from 2 to $16 \mathrm{~h}$ after activation showed that in treatments I, D, IS, ID and ISD, as early as at the 2 -h collection moment, there were less $(p<0.05)$ oocytes in MII (77.8, 0.0, 80.0, 25.0 and 50.0\%, respectively) than in IVF-Control group (100\%). Similar pattern was observed in several activation treatments until $14 \mathrm{~h}$. On the contrary, oocytes arrested in MII in treatment I at $16 \mathrm{~h}$ and in $\mathrm{C}$ from 8 to $16 \mathrm{~h}$ occurred more frequently $(p<0.05)$ than in IVF-Control (Fig. 1a).

In Fig. 1b, showing progression to anaphase/ telophase II $(\mathrm{A} / \mathrm{T})$ stage, there were more $(p<0.05)$ oocytes in A/T in treatments I, IS and ISD (22.2, 20.0 and $50.0 \%$, respectively) at $2 \mathrm{~h}$ compared to IVF-Control 

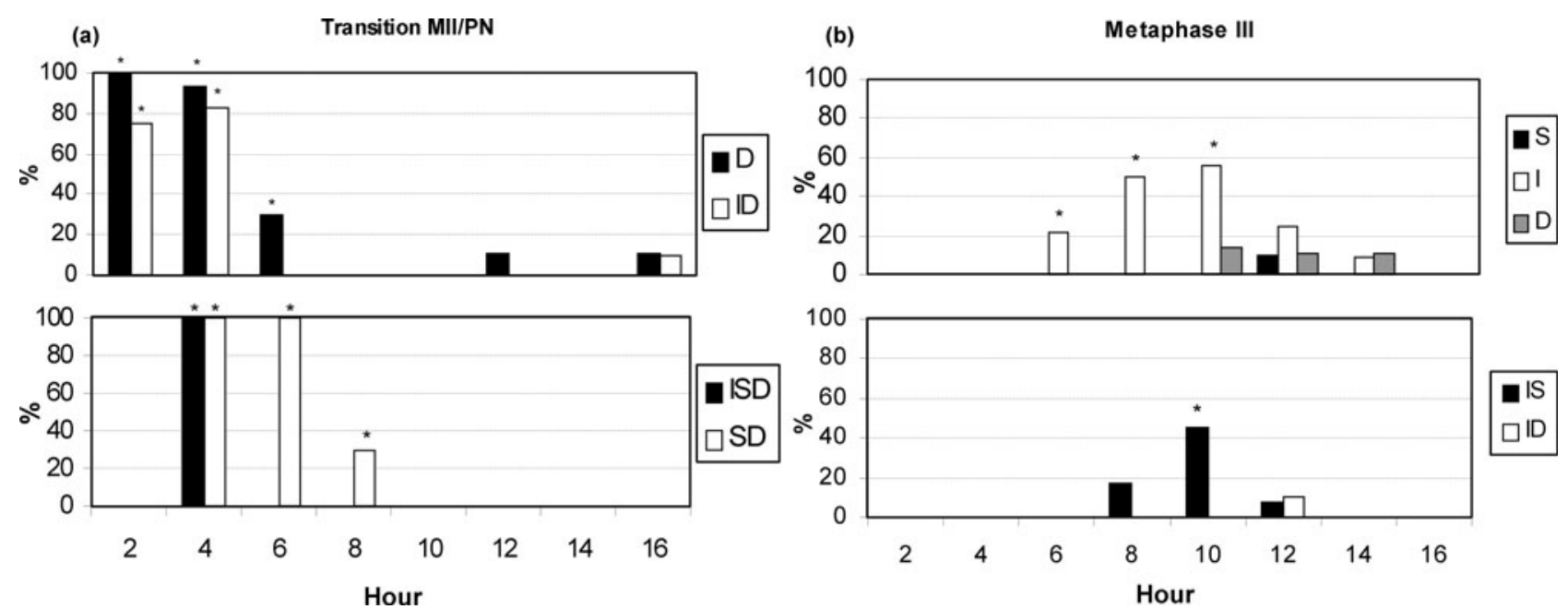

Figure 2 Unusual progression of bovine oocytes through transition metaphase II/pronucleus (MII/PN; $a$ ) and metaphase III (b) stages from 2 to $16 \mathrm{~h}$ after the onset of artificial activation: $20 \mathrm{mM}$ strontium for $6 \mathrm{~h}(\mathrm{~S}) ; 5 \mu \mathrm{M}$ ionomycin for $5 \mathrm{~min}$ (I); 2 mM 6-DMAP for $4 \mathrm{~h}$ (D); treatment I followed by treatment S (IS); treatments I and D (ID); treatments I, S and D (ISD); and treatments $\mathrm{S}$ and $\mathrm{D}(\mathrm{SD})$. Asterisk $(*)$ indicates significantly different $(p<0.05)$ from IVF-Control.

$(0.0 \%)$. The same occurred in treatments IS at $4 \mathrm{~h}(44.4 \%)$ and $\mathrm{S}$ at 8 and $10 \mathrm{~h}$ ( 88.9 and $77.8 \%$, respectively), which were superior $(p<0.05)$ to IVF-Control $(5.0,42.1$ and $5.0 \%$, respectively). Conversely, A/T stage percentage in ID, ISD, SD and C at $8 \mathrm{~h}(0.0 \%$ for all $)$ was inferior $(p<0.05)$ to IVF-Control $(42.1 \%)$.

The first evidence of pronuclear development (Fig. $1 c$ ) in IVF-Control was at $10 \mathrm{~h}$ and pronuclear rates increased progressively until $20 \mathrm{~h}$ (data shown only until 16h). Pronuclear stage started earlier in activated oocytes, because treatments D, ID and ISD at $6 \mathrm{~h}$ (40.0, 100 and 100\%, respectively) and $8 \mathrm{~h}$ (22.2, 100 and $100 \%$, respectively) and IS at $8 \mathrm{~h}(33.3 \%)$ presented higher pronuclear rates $(p<0.05)$ than IVF-Control $(0.0 \%$ for both 6 and $8 \mathrm{~h})$. Conversely, I and $\mathrm{C}$ were inferior $(p<0.05)$ to IVF-Control from 10 to $16 \mathrm{~h}$.

Oocytes treated with single (D) or combined 6-DMAP (ID, ISD and SD) presented a pronucleuslike structure, smaller than a completely formed pronucleus and with more condensed chromatin and that was formed directly from the MII chromosomes without neither second meiosis completion nor sister chromatid segregation. Meiotic spindle disruption was observed after these treatments, followed by decondensation of chromosomes on the metaphase plate and development of the mentioned pronucleuslike structure. We called this developmental stage as transition MII/PN and it was significantly apparent $(p<0.05$; Fig. $2 a)$ in treatment D at 2,4 and $6 \mathrm{~h}(100$, 93.3 and $30.0 \%$, respectively); in ID at 2 and $4 \mathrm{~h}$ (75.0 and $83.3 \%$, respectively); in ISD at $4 \mathrm{~h}(100 \%)$; and in SD at 4, 6 and $8 \mathrm{~h}$ (100, 10.0 and 30.0\%, respectively).

Metaphase III (MIII) is observed in activated oocytes that resume second meiosis division with 2 nd $\mathrm{PB}$ emission, but fail to progress through development and exhibit another metaphase arrest, named MIII. This stage was observed in several activation treatments (Fig. $2 b)$, but it was only significant $(p<0.05)$ in treatment $\mathrm{I}$ at 6,8 and $10 \mathrm{~h}(22.2,50.0$ and $55.6 \%$, respectively) and in IS at $10 \mathrm{~h}(44.4 \%)$.

\section{Pronuclear development and status, cleavage and blastocyst development and quality}

Regarding to pronuclear development (Table 1), best treatments $(p<0.05)$ were ISD $(81.7 \%)$ at $22 \mathrm{~h} ; \mathrm{D}$ $(66.7 \%)$, IS (63.3\%), ID (73.3\%) and ISD (76.7\%) at $26 \mathrm{~h}$; and D (86.7\%), IS (85.0\%) and ID (78.3\%) at $30 \mathrm{~h}$.

Pronuclear status was evaluated by the number of pronuclei (PN) and polar bodies (PB) at 15 to $16 \mathrm{~h}$ after activation (Table 2). Only zygotes with $1 \mathrm{PN}$ were observed in treatments $\mathrm{S}$ and I. In S, there were zygotes with 1 and $2 \mathrm{~PB}$ (35.7 and 60.7\%, respectively) and in I, with 0,1 and $2 \mathrm{~PB}(14.3,57.1$ and $28.6 \%$, respectively). Zygotes 1PN/2PB were more frequent $(p<0.05)$ in IS $(77.4 \%)$ and $1 \mathrm{PN} / 1 \mathrm{~PB}$ zygotes in D (56.3\%), ID (89.1\%), ISD $(65.4 \%)$ and SD (73.9\%). In treatments D (3.1\%) and ISD $(3.8 \%)$, 3PN zygotes were observed.

Higher cleavage rates $(p<0.05)$ were obtained in treatments ISD $(80.0 \%)$ at $22 \mathrm{~h}$; ID $(83.3 \%)$ and ISD $(91.7 \%)$ at $26 \mathrm{~h}$; and I (86.7\%), IS (90.0\%), ID (85.0\%) and ISD $(95.0 \%)$ at $30 \mathrm{~h}$ (Table 1$)$.

For blastocyst development, treatments ID (25.0\%) and ISD (18.3\%) at $22 \mathrm{~h}$; and ID at $26 \mathrm{~h}(45.0 \%)$ and $30 \mathrm{~h}$ $(50.0 \%)$ were the best $(p<0.05$; Table 1$)$.

Observing single treatments (Table 1), at $22 \mathrm{~h}, \mathrm{~S}$ $(33.3 \%)$ presented pronuclear development similar $(p>0.05)$ to $\mathrm{D}(30.0 \%)$, but it was the best $(p<0.05)$ in cleavage (53.3\%); and I (1.7\%), S (1.7\%) and D (5.0\%) 
Table 1 Pronuclear development (PN), cleavage and blastocyst development rates in bovine oocytes after in vitro maturation (IVM) for 22,26 , or $30 \mathrm{~h}$ and activation with different treatments*

\begin{tabular}{cccccc}
\hline IVM & Treatment & $n$ & PN $n(\%)$ & Cleavage $n(\%)$ & Blastocyst $n(\%)$ \\
\hline $22 \mathrm{~h}$ & $\mathrm{C}$ & 60 & $2(3.3 \%)^{i}$ & $6(10.0 \%) 1$ & $0(0.0 \%)^{g}$ \\
& S & 60 & $20(33.3 \%)^{h}$ & $32(53.3 \%)^{g-i}$ & $1(1.7 \%)^{f, g}$ \\
& I & 60 & $3(5.0 \%)^{i}$ & $2(3.3 \%)^{1}$ & $1(1.7 \%)^{f, g}$ \\
& D & 60 & $18(30.0 \%)^{h}$ & $15(25.5 \%)^{k}$ & $3(5.0 \%)^{e-g}$ \\
& IS & 60 & $17(28.3 \%)^{h}$ & $27(45.0 \%)^{h, i}$ & $3(5.0 \%)^{e-g}$ \\
& ID & 60 & $31(51.7 \%)^{f, g}$ & $38(63.3 \%)^{f, g}$ & $15(25.0 \%)^{b}$ \\
& ISD & 60 & $49(81.7 \%)^{a-c}$ & $48(80.0 \%)^{b-e}$ & $11(18.3 \%)^{b-d}$ \\
& C & 60 & $5(8.3 \%)$ & $3(5.0 \%)^{l}$ & $1(1.7 \%)^{f, g}$ \\
& S & 60 & $36(60.0 \%)^{e, f}$ & $40(66.7 \%)^{e-g}$ & $8(13.3 \%)^{b-e}$ \\
& I & 60 & $22(36.7 \%)^{g, h}$ & $37(61.7 \%)^{f-h}$ & $8(13.3 \%)^{b-e}$ \\
& D & 60 & $40(66.7 \%)^{c-f}$ & $42(70.0 \%)^{d-g}$ & $13(21.7 \%)^{b}$ \\
& IS & 60 & $38(63.3 \%)^{d-f}$ & $46(76.7 \%)^{c-f}$ & $5(8.3 \%)^{d-h}$ \\
& ID & 60 & $44(73.3 \%)^{b-e}$ & $50(83.3 \%)^{b-d}$ & $27(45.0 \%)^{a}$ \\
& ISD & 60 & $46(76.7 \%)^{a-d}$ & $55(91.7 \%)^{a, b}$ & $12(20.0 \%)^{b, c}$ \\
& SD & 60 & $19(31.7 \%)^{h}$ & $26(41.7 \%)^{i, j}$ & $4(6.7 \%)^{d-f}$ \\
& C & 60 & $16(26.7 \%)^{h}$ & $16(26.7 \%)^{j, k}$ & $3(5.0 \%)^{e-g}$ \\
& S & 60 & $32(53.5 \%)^{f, g}$ & $44(73.3 \%)^{c-f}$ & $3(5.0 \%)^{e-g}$ \\
& I & 60 & $38(63.3 \%)^{d-f}$ & $52(86.7 \%)^{a-c}$ & $11(18.3 \%)^{b-d}$ \\
& D & 60 & $52(86.7 \%)^{a}$ & $41(68.3 \%)^{d-g}$ & $8(13.3 \%)^{b-e}$ \\
& IS & 60 & $51(85.0 \%)^{a, b}$ & $54(90.0 \%)^{a, b}$ & $11(18.3 \%)^{b-d}$ \\
& ID & 60 & $47(78.3 \%)^{a-d}$ & $51(85.0 \%)^{a-c}$ & $30(50.0 \%)^{a}$ \\
ISD & 60 & $45(75.0 \%)^{b-e}$ & $57(95.0 \%)^{a}$ & $9(15.0 \%)^{b-e}$ \\
& SD & 60 & $20(33.3 \%)^{h}$ & $27(45.0 \%)^{i}$ & $2(3.3 \%)^{f, g}$ \\
\hline
\end{tabular}

\footnotetext{
${ }^{a-i}$ Values with different superscripts within columns are significantly different $(p<0.05)$.

*PN was assessed at 15 to $16 \mathrm{~h}$; cleavage at 46 to $48 \mathrm{~h}$; and blastocyst development on Day 7. The activation treatments were: control group (C); $20 \mathrm{mM}$ strontium for $6 \mathrm{~h}(\mathrm{~S}) ; 5 \mu \mathrm{M}$ ionomycin for $5 \mathrm{~min}$ (I); $2 \mathrm{mM}$ 6-DMAP for $4 \mathrm{~h}$ (D); treatment I followed by treatment $S$ (IS); treatments I and D (ID); treatments I, S and D (ISD); and treatments S and D (SD).
}

Table 2 Pronuclear status in bovine zygotes at 15 to $16 \mathrm{~h}$ after activation of oocytes in vitro matured for $26 \mathrm{~h}^{*}$

\begin{tabular}{|c|c|c|c|c|c|c|c|}
\hline \multirow[b]{2}{*}{$\mathrm{T}$} & \multirow[b]{2}{*}{$n$} & \multicolumn{3}{|c|}{$1 \mathrm{PN}$} & \multicolumn{2}{|c|}{$2 \mathrm{PN}$} & \multirow{2}{*}{$\frac{3 \mathrm{PN}}{1 \mathrm{~PB} n(\%)}$} \\
\hline & & OPB $n(\%)$ & $1 \mathrm{~PB} n(\%)$ & $2 \mathrm{~PB} n(\%)$ & $1 \mathrm{~PB} n(\%)$ & $2 \mathrm{~PB} n(\%)$ & \\
\hline$S$ & 28 & $1^{a, B}(3.6)$ & $10^{c, d, A}(35.7)$ & $17^{a, b, A}(60.7)$ & - & - & - \\
\hline I & 7 & $1^{a, A}(14.3)$ & $4^{b, c, A}(57.1)$ & $2^{b, c, A}(28.6)$ & - & - & - \\
\hline $\mathrm{D}$ & 32 & $4^{a, B, C}(12.5)$ & $18^{b, c, A}(56.3)$ & $7^{c, B}(21.9)$ & $1^{a, C}(3.1)$ & $1^{C}(3.1)$ & $1^{a, C}(3.1)$ \\
\hline IS & 31 & $1^{a, B}(3.2)$ & $5^{d, B}(16.2)$ & $24^{a, A}(77.4)$ & $1^{a, B}(3.2)$ & - & - \\
\hline ID & 55 & $6^{a, B}(10.9)$ & $49^{a, A}(89.1)$ & - & - & - & - \\
\hline ISD & 52 & $2^{a, c}(3.8)$ & $34^{b, A}(65.4)$ & $6^{c, B, C}(11.6)$ & $8^{a, B}(15.4)$ & - & $2^{a, C}(3.8)$ \\
\hline SD & 23 & $1^{a, B}(4.4)$ & $17^{a, b, A}(73.9)$ & $3^{c, B}(13.0)$ & $2^{a, B}(8.7)$ & - & - \\
\hline
\end{tabular}

$a, b, c$ Values with different superscripts within columns are significantly different $(p<0.05)$.

$A, B, C$ Values with different superscripts within rows are significantly different $(p<0.05)$.

${ }^{*}$ Number of pronuclei (PN) and polar bodies (PB). The activation treatments were: $20 \mathrm{mM}$ strontium for $6 \mathrm{~h}$ (S); $5 \mu \mathrm{M}$ ionomycin for $5 \mathrm{~min}$ (I); $2 \mathrm{mM}$ 6-DMAP for $4 \mathrm{~h}$ (D); treatment I followed by treatment $\mathrm{S}$ (IS); treatments I and D (ID); treatments I, S and D (ISD); and treatments S and D (SD).

were similar $(p>0.05)$ in blastocyst development. At $26 \mathrm{~h}, \mathrm{~S}(60.0 \%)$ and D $(66.7 \%)$ were similar $(p>$ $0.05)$ and superior $(p<0.05)$ to I $(36.7 \%)$ in pronuclear development; but they were all similar $(p>0.05)$ in cleavage $(61.7$ to $70.0 \%)$ and blastocyst development (13.3 to $21.7 \%)$. At $30 \mathrm{~h}, \mathrm{D}(86.7 \%)$ was superior $(p<0.05)$ to $S(53.5 \%)$ and I $(63.3 \%)$ for pronuclear development; I $(86.7 \%)$ was superior $(p<0.05)$ to $\mathrm{D}$ $(68.3 \%)$ in cleavage; and I $(18.3 \%)$ and D $(13.3 \%)$ were similar $(p>0.05)$ in blastocyst development.

Also in Table 1, regarding the association of two drugs, IS was similar $(p>0.05)$ to $S$, respectively, in 
Table 3 Cell number (mean \pm SD) in ICM, TE and total and ICM/total cell ratio in expanded blastocysts obtained after 7 day-culture of bovine oocytes in vitro matured (IVM) for 22, 26, or $30 \mathrm{~h}$ and activated with different treatments*

\begin{tabular}{lcrcccc}
\hline IVM & Treatment & $n$ & ICM (mean \pm SD) & TE (mean \pm SD) & Total (mean \pm SD) & ICM/total \\
\hline $22 \mathrm{~h}$ & D & 1 & $22^{b-d}$ & $88^{a}$ & $110^{a}$ & $0.20^{d, e}$ \\
& ID & 9 & $25 \pm 17^{a-d}$ & $64 \pm 32^{a-c}$ & $89 \pm 47^{a-c}$ & $0.28^{b-d}$ \\
& ISD & 7 & $22 \pm 14^{b-d}$ & $69 \pm 15^{a-c}$ & $91 \pm 23^{a-c}$ & $0.24^{c, d}$ \\
& SD & 1 & $3^{e}$ & $41^{d, e}$ & $44^{e}$ & $0.07^{f}$ \\
& S & 5 & $24 \pm 10^{a-d}$ & $68 \pm 9^{a-c}$ & $92 \pm 15^{a, b}$ & $0.26^{b-d}$ \\
& I & 4 & $25 \pm 11^{a-d}$ & $69 \pm 23^{a-c}$ & $95 \pm 19^{a, b}$ & $0.26^{b-d}$ \\
& D & 6 & $37 \pm 5^{a, b}$ & $31 \pm 11^{e}$ & $67 \pm 16^{c, d}$ & $0.55^{a}$ \\
& IS & 5 & $24 \pm 4^{a-d}$ & $64 \pm 10^{a-c}$ & $89 \pm 8^{a-c}$ & $0.27^{b-d}$ \\
& ID & 18 & $39 \pm 17^{a}$ & $65 \pm 27^{a-c}$ & $104 \pm 35^{a}$ & $0.38^{a-c}$ \\
& ISD & 9 & $17 \pm 9^{d}$ & $66 \pm 17^{a-c}$ & $83 \pm 21^{a-c}$ & $0.20^{d, e}$ \\
& SD & 2 & $21 \pm 4^{c, d}$ & $80 \pm 8^{a, b}$ & $101 \pm 5^{a}$ & $0.21^{d, e}$ \\
& C & 1 & $7^{e}$ & $50^{c, d}$ & $57^{d, e}$ & $0.12^{e, f}$ \\
& I & 7 & $32 \pm 23^{a-c}$ & $67 \pm 35^{a-c}$ & $99 \pm 50^{a}$ & $0.32^{b-d}$ \\
& D & 3 & $25 \pm 9^{a-d}$ & $77 \pm 22^{a, b}$ & $102 \pm 19^{a}$ & $0.25^{c, d}$ \\
& IS & 7 & $22 \pm 7^{b-d}$ & $51 \pm 13^{c, d}$ & $72 \pm 14^{b-d}$ & $0.31^{b-d}$ \\
& ID & 14 & $34 \pm 24^{a-c}$ & $61 \pm 28^{b, c}$ & $95 \pm 37^{a, b}$ & $0.36^{b, c}$ \\
& ISD & 1 & $21 \pm 4^{c, d}$ & $63 \pm 8^{b, c}$ & $84 \pm 7^{a-c}$ & $0.25^{c, d}$ \\
& SD & 1 & $38^{a}$ & $53^{c, d}$ & $91^{a, b, c}$ & $0.42^{a, b}$ \\
\hline
\end{tabular}

$a-f$ Values with different superscripts within columns are significantly different $(p<0.05)$.

*ICM: inner cell mass; TE: trophectoderm. The activation treatments were: control group (C); $20 \mathrm{mM}$ strontium for $6 \mathrm{~h}(\mathrm{~S}) ; 5 \mu \mathrm{M}$ ionomycin for $5 \mathrm{~min}$ (I); $2 \mathrm{mM}$ 6-DMAP for $4 \mathrm{~h}$ (D); treatment I followed by treatment $\mathrm{S}$ (IS); treatments I and D (ID); treatments I, S and D (ISD); and treatments S and D (SD).

pronuclear, cleavage and blastocyst development at $22 \mathrm{~h}$ ( 28.3 vs. $33.3 \%, 45.0$ vs. $53.3 \%$ and 5.0 vs. $1.7 \%)$ and 26 h (63.3 vs. $60.0 \%, 76.7$ vs. $66.7 \%$ and 8.3 vs. $13.3 \%)$, but IS $(85.0,90.0$ and $18.3 \%)$ was superior $(p<0.05)$ to $S$ (53.5, 73.3 and $5.0 \%)$ at $30 \mathrm{~h}$. When IS was compared to I, it was superior $(p<0.05)$ in pronuclear development at $22 \mathrm{~h}(28.3$ vs. $5.0 \%), 26 \mathrm{~h}(63.3 \mathrm{vs} .36 .7 \%)$ and $30 \mathrm{~h}$ ( 85.0 vs. $63.3 \%)$ and in cleavage at $22 \mathrm{~h}(45.0$ vs. $3.3 \%)$. Treatment ID was superior $(p<0.05)$ to I and D in all evaluations at $22 \mathrm{~h}$ and ID was superior $(p<0.05)$ to $\mathrm{D}$ in cleavage at $30 \mathrm{~h}(85.0$ vs. $68.3 \%)$ and in blastocyst development at $26 \mathrm{~h}(45.0$ vs. $21.7 \%)$ and $30 \mathrm{~h}(50.0$ vs. $13.3 \%)$. ID was frequently superior $(p<0.05)$ to I, except in pronuclear development $(78.3$ vs. $63.3 \%)$ and cleavage ( 85.0 vs. $86.7 \%)$ at $30 \mathrm{~h}$. Treatment SD was similar $(p>0.05)$ to $\mathrm{S}$ and/or $\mathrm{D}$ at $22 \mathrm{~h}$, but inferior $(p<0.05)$ at 26 and $30 \mathrm{~h}$ in all evaluations (Table 1$)$.

Three-treatment combination ISD was superior $(p<0.05)$ to $\mathrm{S}, \mathrm{I}, \mathrm{D}, \mathrm{IS}$ and/or ID in pronuclear development and cleavage at $22 \mathrm{~h}$. Conversely, ISD was inferior $(p<0.05)$ to ID in blastocyst development at $26 \mathrm{~h}(20.0$ vs. $45.0 \%)$ and $30 \mathrm{~h}(15.0$ vs. $50.0 \%)$ and to $\mathrm{D}$ in pronuclear development at $30 \mathrm{~h}(75.0$ vs. $86.7 \%$; Table 1).

Total, ICM and TE cell numbers and ICM/total cell ratio were assessed for blastocyst quality evaluation in expanded blastocysts (Table 3). At $22 \mathrm{~h}$, SD presented the lowest $(p<0.05)$ ICM, TE and total cell mean
$( \pm \mathrm{SD})$ number and ICM/total cell ratio $(3,41,44$ and 0.07 , respectively) compared to $\mathrm{D}(22,88,110$ and 0.20), ID (25 $\pm 17,64 \pm 32,89 \pm 47$ and 0.28) and ISD $(22 \pm 14,69 \pm 15,91 \pm 23$ and 0.24). For ICM cell number, the highest $(p<0.05)$ values $(p<0.05)$ occurred in treatments D $(37 \pm 5)$ and ID $(39 \pm 17)$ at $26 \mathrm{~h}$; and SD (38) at $30 \mathrm{~h}$. For TE cell number, $\mathrm{D}(31 \pm 11)$ was the worst $(p<0.05)$ at $26 \mathrm{~h}$, but the best $(77 \pm 22)$ at $30 \mathrm{~h}$. For total cell number, the best treatments were ID $(104 \pm 35)$ and SD $(101 \pm 5)$ at $26 \mathrm{~h}$; and I $(99 \pm 50)$ and D $(102 \pm 19)$ at $30 \mathrm{~h}$. The highest $(p<0.05) \mathrm{ICM} /$ total cell ratio was observed in $\mathrm{D}(0.55)$ at $26 \mathrm{~h}$; and in SD (0.42) at $30 \mathrm{~h}$ (Table 3 ).

\section{Discussion}

\section{Immunofluorescent evaluation of tubulin and chromatin}

Immunofluorescent evaluation of tubulin and chromatin was used to assess and compare nuclear dynamics in bovine oocytes after fertilization or artificial activation. In the present work, sperm penetration was observed at 4 h.p.i., which is in agreement with previous descriptions of sperm penetration occurring from 3 h.p.i. (Saeki et al., 1991) to 6 h.p.i. (Xu \& Greve, 1988; Kim et al., 2002). 
There were less oocytes in MII stage from 2 to $10 \mathrm{~h}$ in most activation treatments compared to IVF-Control, indicating earlier meiosis resumption in activated oocytes. At $16 \mathrm{~h}$, in all treatments, except in I and C, MII rates were similar to IVF-Control, confirming that meiosis resumption is a step easily achieved after artificial activation (Verlhac et al., 1994; Liu et al., 1998).

As a consequence of earlier meiosis resumption, cell cycle progression to anaphase/telophase II (A/T) and to pronuclear stages was faster in activated oocytes. In some treatments, besides faster progression, the $\mathrm{A} / \mathrm{T}$ stage lasted longer, since A/T stage reduced at $10 \mathrm{~h}$ in IVF-Control and only at $12 \mathrm{~h}$ in $\mathrm{S}$ and IS treatments.

The first evidence of pronuclear formation in IVFControl was observed at $10 \mathrm{~h}$ after sperm penetration (or 14 h.p.i.). In experiments where sperm penetration occurred at 3 to 6 h.p.i., pronuclear formation was observed 4 to $6 \mathrm{~h}$ later, which means at 10 to 12 h.p.i. (Xu \& Greve, 1988; Saeki et al., 1991). It was demonstrated that longer sperm preincubation to induce capacitation reduces both the time length for sperm penetration and for pronuclear development (Kim et al., 2002). In this way, pronuclear development delay observed here may have been influenced by the IVF procedure, which did not include sperm incubation prior to insemination.

Pronuclear formation timing was very distinct among activation treatments. It was accelerated $4 \mathrm{~h}$ in treatments D, ID and ISD and $2 \mathrm{~h}$ in treatment IS; but it was similar to IVF-Control in treatments S and SD; and delayed $4 \mathrm{~h}$ in treatment I. This evidence may have important application in somatic cell nuclear transfer (SCNT) procedures, since for efficient reprogramming, nuclear envelope breakdown and premature chromatin condensation must occur in order to expose the transferred nucleus to the cytoplasmic oocyte factors necessary for early development (Heindryckx et al., 2002). To increase the transferred nucleus exposition to the ooplasm and thus improving reprogramming potential, many approaches have been tested as recloning or serial nuclear transfer (reviewed by Peura \& Trounson, 1998), increased time between fusion and activation (De Sousa et al., 2002) or utilization of enucleated prophase I oocytes as recipient cytoplasms (Polanski et al., 2005). Since activation treatments using 6-DMAP, especially D, ID and ISD, accelerate pronuclear formation, anticipating nuclear envelope organization, they may reduce the exposition of the karyoplast to the recipient cytoplasm when used in SCNT. This could affect nuclear reprogramming of the transferred nucleus and consequently embryonic development. Then, compared to 6-DMAP, treatments using strontium may benefit nuclear reprogramming in SCNT.

At $16 \mathrm{~h}$, there were more pronuclear stage embryos in treatments IS and ISD than in IVF-Control. This apparent superiority of the activation treatments was due to the evidence that in IVF-Control pronuclear formation rates progressively increased until $20 \mathrm{~h}$ after sperm penetration.

The A/T stage was not observed during incubation with 6-DMAP and, in treatment ISD, this stage disappeared rapidly when 6-DMAP was introduced into the culture media $(2 \mathrm{~h}$ after the beginning of the activation with I and S). This phenomenon was due to direct progression from MII to pronuclear stage, because 6-DMAP is a broad-spectrum phosphorylation inhibitor that disrupts meiotic spindle, inhibits $2 \mathrm{~PB}$ emission and accelerates pronuclear formation, by acting directly through nuclear lamins or indirectly by MAP kinase inactivation (Liu et al., 1998; Loi et al.,1998). All oocytes treated with 6-DMAP presented a pronucleus-like structure that was formed directly from the MII chromosomes. Such condition, named here as transition $\mathrm{MII} / \mathrm{PN}$, was a transitory stage between metaphase II and pronuclear stage. It was observed as early as $2 \mathrm{~h}$ in D and ID treatments and $4 \mathrm{~h}$ in ISD and SD treatments (in which the incubation with 6-DMAP started $2 \mathrm{~h}$ later, due to the use of strontium alone). Since the MII/PN frequency fell after $6 \mathrm{~h}$ in all treatments, this stage lasted only during oocyte exposition to activation medium in the presence of 6DMAP.

Even though in most oocytes activated with 6-DMAP transition MII/PN progressed to the pronuclear stage, in some oocytes treated with $\mathrm{D}$ and $\mathrm{SD}, \mathrm{A} / \mathrm{T}$ stage was observed when 6-DMAP was removed from the media. Thus, we can suppose that MII/PN transition is a reversible stage that can lead to pronuclear stage or return to metaphase II stage, in cases of insufficient activation stimulus. Once in MII, these oocytes remain arrested or progress to $\mathrm{A} / \mathrm{T}$ and pronuclear stages due to spontaneous decrease in MPF activity during oocyte ageing (Kikuchi et al., 1995).

In some oocytes, the unusual pattern of metaphase III (MIII) arrest was observed. MIII occurs in activated oocytes that resume second meiosis division with $2 \mathrm{~PB}$ emission, but fail to progress through development. In these oocytes, chromosomes recondense and originate a structure similar to a metaphase, named MIII (Kubiak, 1989; Araki et al., 1996). It is generated when an activation stimulus, besides promoting MPF inactivation, is insufficient to inactivate MAP kinase and to prevent de novo MPF synthesis (Araki et al., 1996; Liu et al., 1998). It is known that MIII may be avoided by the use of multiple calcium pulses or by the combination of different activation treatments (Vitullo \& Ozil, 1992). In this work, MIII occurred in all treatments except in IVF-Control and ISD and it was significant in treatments I and IS, confirming that activation treatment intensity may account for MIII establishment. Decrease in the number of MIII oocytes during culture period indicated that it is a 
stage that may be overcome by spontaneous decrease in MPF activity as long as oocyte ages (Kikuchi et al., 1995).

\section{Pronuclear development and status, cleavage and blastocyst development and quality}

At fertilization, the sperm cell promotes multiple spikes of intracellular free calcium within the oocytes during several hours: an initial transient is followed by a series of smaller transient increases (Grupen et al., 2002). Activation treatments aim to mimic the events promoted by spermatozoa and may act in distinct pathways. Some promote intracellular free calcium concentration increase in one pulse such as ionomycin (Loi et al., 1998) or in multiple pulses, such as strontium (Cuthbertson et al., 1981). Others promote inhibition of protein synthesis, e.g. cycloheximide (Nussbaum \& Prather, 1995), or protein phosphorylation, e.g. 6-DMAP (Susko-Parrish et al., 1994). Since multiple intracellular calcium pulses are more effective than a single peak for activation (Vitullo \& Ozil, 1992) and treatments that promote a single pulse are frequently associated with protein synthesis or phosphorylation inhibitors, in this study we aimed to compare single and combined treatments of strontium (S), ionomycin (I) and 6-DMAP (D) for activation of bovine oocytes in vitro matured for 22,26 and $30 \mathrm{~h}$.

Pronuclear status in activated oocytes was evaluated by the number of pronuclei (PN) and polar bodies (PB) at 15 to $16 \mathrm{~h}$ after activation treatments. In mice, an interesting research described the relationship between actin filaments, microtubules and parthenogenesis dynamics to the pronuclear status (Webb et al., 1986). When there is a peripheral meiotic spindle over an actin filament-rich area, a zygote with $1 \mathrm{PN} / 2 \mathrm{~PB}$ was formed; while central meiotic spindle and cortical actin promoted immediate cleavage; peripheral spindle and cortical actin induced 2PN/1PB appearance; and disorganized meiotic spindle promoted 1PN/1PB establishment (Webb et al., 1986). In agreement with these findings, in treatments using 6-DMAP (D, ID, ISD and SD) meiotic spindle disruption was evident and the number of $1 \mathrm{PN} / 1 \mathrm{~PB}$ was higher. On the contrary, in $\mathrm{S}$ and IS treatments, where no spindle disruption occurred, $1 \mathrm{PN} / 2 \mathrm{~PB}$ frequency was higher. Summarizing, the latest treatments promoted pronuclear development more similar to that observed after fertilization with $2 \mathrm{~PB}$ emission.

Since all oocytes were selected for $1 \mathrm{~PB}$ presence before activation treatments, $\mathrm{OPB}$ and $1 \mathrm{~PB}$ zygotes may have appeared, respectively, due to degeneration of 2 or $1 \mathrm{~PB}$. In treatments S, I and ID, no zygotes possessing more than 1PN were observed, while in treatment IS and SD there were 2PN zygotes and in $\mathrm{D}$ and ISD, 2PN and 3PN zygotes. Formation of more than two pronuclei in activated oocytes might be caused by premature DNA synthesis that induces karyokinesis before cytokinesis (De La Fuente \& King, 1998). However, it will be necessary to observe DNA synthesis and follow actin dynamics in activated oocytes to confirm this hypothesis.

Treatment ID was the most effective for the production of diploid zygotes (1PN/1PB) and the treatment IS was the best for haploid development $(1 \mathrm{PN} / 2 \mathrm{~PB})$.

It is known that artificial activation success depends on oocyte age (maturation time; Presicce \& Yang, 1994), since activation is more easily achieved in aged oocytes due to spontaneous reduction on MPF activity (Kikuchi et al., 1995). In this experiment, most activation treatments showing higher pronuclear development rates were obtained in oocytes matured for $30 \mathrm{~h}$ compared to $22 \mathrm{~h}$. In control group (C), it was also noticed that increasing IVM culture period resulted in higher pronuclear formation and cleavage rates due to spontaneous activation.

For single treatments in young oocytes (IVM for $22 \mathrm{~h}$ ), the stimulus promoted by S and D was better for pronuclear development and cleavage compared to the single calcium pulse promoted by I. Conversely, treatment I was sufficient for activation of aged oocytes (IVM for $30 \mathrm{~h}$ ). We noticed that strontium was more appropriate than the other single treatments in early matured bovine oocytes (IVM for $22 \mathrm{~h}$ ), maybe because it promotes multiple calcium increases in bovine, as observed in mice (Bos-Mikich et al., 1995).

Another observation is that 6-DMAP was more efficient when there was an initial reduction on MPF activity that may be promoted by a calcium increase (in combined treatments ID and ISD) or by MPF spontaneous reduction during oocyte ageing (in treatment $\mathrm{D}$ at 26 and $30 \mathrm{~h}$ ).

For young oocytes (IVM for $22 \mathrm{~h}$ ), a stronger stimulus was necessary for achieving higher activation and cleavage rates and it was obtained using the three-combined treatment ISD. This is in agreement with previous observation showing that oocyte age influence on parthenogenetic activation can be minimized by promotion of multiple intracellular calcium pulses (Vitullo \& Ozil, 1992) or by combination of different artificial activation treatments (Yang et al., 1994; Liu et al., 1998). This beneficial effect of combining treatments was observed in ID compared to D. However, IS was similar to $S$ in activation, cleavage and blastocyst development rates, confirming strontium ability to activate by itself young oocytes.

According to the information that aged oocytes are easier to be activated, more artificial treatments were able to promote high activation and development rates after IVM for 26 and $30 \mathrm{~h}$ than for $22 \mathrm{~h}$. At $26 \mathrm{~h}$, combined treatments IS and ID did not 
improve activation and cleavage rates obtained in single treatments $\mathrm{S}$ and $\mathrm{D}$, but blastocyst formation in ID was superior to all treatments. However, at $30 \mathrm{~h}$, combined treatments improved activation and cleavage rates, since IS was superior to $S$ in activation and ID and IS were, respectively, superior to D and $S$ in cleavage and blastocyst. It is interesting to notice that for single activation treatments oocyte ageing influence was evident as soon as IVM for $26 \mathrm{~h}$ compared to 22 $\mathrm{h}$, while in combined treatments a longer ageing was necessary since its effect was only observed at $30 \mathrm{~h}$. Thus, a smaller MPF reduction due to ageing from 22 to $26 \mathrm{~h}$ provokes more effects in single treatments than in combined ones that required longer ageing and possible stronger spontaneous decline on MPF activity.

Activation and blastocyst development rates in treatments ISD and SD were not influenced by oocyte age. Treatment ISD promoted the highest activation stimulus, since it was a combination of three different agents. This can be the reason why it was successful in promoting higher rates of activation and did not require further ageing (or spontaneous MPF decline) to be effective. However, SD treatment promoted lower rates of activation and development in all evaluated moments. This was the first report in bovine of a combined treatment using strontium and 6-DMAP (ISD and SD) and we can observe that, without ionomycin (in treatment SD), it was not an effective combination for artificial activation. Furthermore, SD was inferior to both single treatments $S$ and $D$ in activation and cleavage at 26 and $30 \mathrm{~h}$ and to D in blastocyst development at 26 and $30 \mathrm{~h}$.

In mice, a recent work described interesting results using strontium followed not simultaneously by 6DMAP (Ma et al., 2005). Higher blastocyst rates and ICM cell number were achieved in younger oocytes, but the combination of strontium and 6-DMAP was harmful for aged oocytes. Here, we observed similar developmental rates at 22,26 and $30 \mathrm{~h}$ in ISD and $\mathrm{SD}$, so these treatments were not influenced by oocyte age. However, comparing D and ID to ISD and SD at 26 and $30 \mathrm{~h}$ we observed the detrimental effect of using the combination of strontium and 6-DMAP in aged oocytes. Maybe the stimulus promoted by this association is excessive in aged oocytes that already present a spontaneous decrease in MPF activity. This event was also observed in ISD treatment: besides higher rates of activation and cleavage at $22 \mathrm{~h}$, blastocyst development rates for ISD compared to ID were similar at $22 \mathrm{~h}$ and inferior at 26 and $30 \mathrm{~h}$. In addition, ISD was inferior to D in activation and cleavage at $30 \mathrm{~h}$. Then, the strong ISD stimulus able to promote efficient activation and cleavage can have detrimental effects on further embryonic development, similar to the cytotoxicity observed after excessive long-lasting calcium increase (Loi et al., 1998). In addition, that condition may be influenced by oocyte age.

Bovine blastocysts are constituted by two morphologically distinct cell groups: (1) inner cell mass (ICM), which forms the embryo; and (2) trophectoderm (TE), which forms the placenta (Stojkovic et al., 1998). Thus, the number of embryos reaching the blastocyst stage is as important for evaluation of embryonic development as their quality. Blastocyst quality can be estimated by ICM and TE cell number as much as by ICM/total cell ratio (Bos-Mikich et al., 1997), since lower cell number in ICM affects embryo viability and lower number of TE cells is detrimental for placental development (Koo et al., 2002).

Detrimental effects of treatment SD previously mentioned in this work were also observed for blastocyst quality, with reduction in ICM cell number at 22 and $26 \mathrm{~h}$, but the reduction in TE cell number at $30 \mathrm{~h}$ resulted in higher ICM/total cell ratio for SD at this time of activation. Comparing treatments with similar ICM cell number, ICM/total cell ratio was similar for ID and ISD at $22 \mathrm{~h}$; for S, I and IS at $26 \mathrm{~h}$; and for I, D, IS, ID and ISD at $30 \mathrm{~h}$. Therefore, all these treatments allowed the development of similar quality embryos.

In summary, we observed that single or combined treatment of strontium, ionomycin and 6-DMAP influenced cell cycle kinetics and embryo development to different extents. This information can be used to comprehend mechanisms of oocyte activation and to guide experimental design of researches in this area. For example, ISD is useful to promote higher activation and cleavage rates in young oocytes. Treatments $S$ and IS show cell cycle progression and pronuclear formation timing similar to fertilization and they are probably more efficient for nuclear reprogramming. Treatment ID, which promoted higher blastocyst development rates, can be used to obtain embryos for studies on early embryonic development events or on genomic imprinting processes after parthenogenetic activation. We conclude that association of strontium and 6-DMAP was only effective when it was also combined to ionomycin and applied in young bovine oocytes. Despite the lower influence of oocyte age in treatments using strontium, there is a detrimental effect of associating strontium to 6-DMAP in aged oocytes.

\section{Acknowledgments}

This work was supported by FAPESP: grant \# 00/00006-9 and 02/00971-1.

\section{References}

Araki, K., Naito, K., Haraguchi, S., Suzuki, R., Yokoyama, M., Inoue, M., Aizawa, S., Toyoda, Y. \& Sato, E. (1996). Meiotic abnormalities of c-mos knockout mouse oocytes: activation 
after first meiosis or entrance into third meiotic metaphase. Biol. Reprod. 55, 1315-24.

Bos-Mikich, A., Wood, M.J., Candy, C.J. \& Whittingham, D.G. (1995). Cytogenetical analysis and developmental potential of vitrified mouse oocytes. Biol. Reprod. 53, 780-5.

Bos-Mikich, A., Whittingham, D.G. \& Jones, K.T. (1997). Meiotic and mitotic $\mathrm{Ca}^{2+}$ oscillations affect cell composition in resulting blastocysts. Dev. Biol. 182, 172-9.

Cuthbertson, K.S.R., Whittingham, D.G. \& Cobbold, P.H. (1981). Free Ca2+ increases in exponential phases during mouse oocyte activation. Nature 294, 754-7.

De La Fuente, R. \& King, W.A. (1998). Developmental consequences of karyokinesis without cytokinesis during the first mitotic cell cycle of bovine parthenotes. Biol. Reprod. 58, 952-62.

De Sousa, P.A., Dobrinsky, J.R., Zhu, J., Archibald, A.L., Ainslie, A., Bosma, W., Bowering, J., Bracken, J., Ferrier, P.M., Fletcher, J., Gasparrini, B., Harkness, L., Johnston, P., Ritchie, M., Ritchie, W.A., Travers, A., Albertini, D., Dinnyes, A., King, T.J. \& Wilmut, I. (2002). Somatic cell nuclear transfer in the pig: control of pronuclear formation and integration with improved methods for activation and maintenance of pregnancy. Biol. Reprod. 66, 64250.

Dupont, G. (1998). Link between fertilization-induced $\mathrm{Ca}^{2+}$ oscillations and relief from metaphase II arrest in mammalian eggs: a model based on calmodulin-dependent kinase II activation. Biophys. Chem. 72, 153-67.

Grupen, C.G., Nottle, M.B. \& Nagashima, H. (2002). Calcium release at fertilization: artificially mimicking the oocyte's response to sperm. J. Reprod. Dev. 48, 313-33.

Heindryckx, B., Rybouchkin, A., Van Der Elst, J. \& Dhont, M. (2002). Serial pronuclear transfer increases the developmental potential of in vitro-matured oocytes in mouse cloning. Biol. Reprod. 67, 1790-5.

Kikuchi, K., Izaike, Y., Noguchi, J., Furukawa, T., Daen, F.P., Naito, K. \& Toyoda, Y. (1995). Decrease of histone H1 kinase activity in relation to parthenogenetic activation of pig follicular oocytes matured and aged in vitro. J. Reprod. Fertil. 105, 325-30.

Kim, B-K., Lee, S-C., Lee, K-S., Lee, B-K., Han, C-H., Kim, J-H. \& Lee, C-S. (2002). Effect of medium milieu on sperm penetration and pronuclear formation of bovine oocytes matured in vitro. Theriogenology 57, 2093-104.

Kishikawa, H., Wakayama, T. \& Yanagimachi, R. (1999). Comparison of oocyte-activating agents for mouse cloning. Cloning 1, 153-9.

Koo, D-B., Kang, Y-K., Choi, Y-H., Park, J.S., Kim, H-N., Oh, K.B., Son, D-S., Park, H., Lee, K.K. \& Han, Y-M. (2002). Aberrant allocations of inner cell mass and trophectoderm cells in bovine nuclear transfer blastocysts. Biol. Reprod. 67, 487-92.

Kubiak, J.Z. (1989). Mouse oocytes gradually develop the capacity for activation during the metaphase II arrest. Dev. Biol. 136, 537-45.

Küpker, W., Diedrich, K. \& Edwards, R.G. (1998). Principles of mammalian fertilization. Hum. Reprod. 13, 20-32.

Liu, L., Ju, J-C. \& Yang, X. (1998). Differential inactivation of maturation-promoting factor and mitogen-activated protein kinase following parthenogenetic activation of bovine oocytes. Biol. Reprod. 59, 537-45.
Loi, P., Ledda, S., Fulka Jr, J., Cappai, P. \& Moor, R.M. (1998). Development of parthenogenetic and cloned ovine embryos: effect of activation protocols. Biol. Reprod. 58, 1177-87.

Loren, J. \& Lacham-Kaplan, O. (2006). The employment of strontium to activate mouse oocytes: effects on spermatidinjection outcome. Reproduction 131, 259-67.

Ma, S-F., Liu, X-Y., Miao, D-Q, Han, Z-B., Zhang, X., Miao, Y-L., Yanagimachi, R. \& Tan, J-H. (2005). Parthenogenetic activation of mouse oocytes by strontium chloride: a search for the best conditions. Theriogenology 64, 114257.

Malcuit, C., Maserati, M., Takahashi, Y., Page, R. \& Fissore, R.A. (2006). Intracytoplasmic sperm injection in the bovine induces abnormal $\left[\mathrm{Ca}^{2+}\right]_{\mathrm{i}}$ responses and oocyte activation. Reprod. Fertil. Dev. 18, 39-51.

Méo, S.C., Leal, C.L.V. \& Garcia, J.M. (2004). Activation and early parthenogenesis of bovine oocytes treated with ethanol and strontium. Anim. Reprod. Sci. 81, 35-46.

Méo, S.C., Yamazaki, W., Leal, C.L.V., Oliveira, J.A. de \& Garcia, J.M. (2005). Use of strontium for bovine oocyte activation. Theriogenology 63, 2089-102.

Nakada, K. \& Mizuno, J. (1998). Intracellular calcium responses in bovine oocytes induced by spermatozoa and by reagents. Theriogenology 50, 269-82.

Nussbaum, D.J. \& Prather, R.S. (1995). Differential effects of protein synthesis inhibitors on porcine oocyte activation. Mol. Reprod. Dev. 41, 70-5.

Peura, T.T. \& Trounson, A.O. (1998). Recycling bovine embryos for nuclear transfer. Reprod. Fertil. Dev. 10, 62732.

Polanski, Z., Hoffmann, S. \& Tsurumi, C. (2005). Oocyte nucleus controls progression through meiotic maturation. Dev. Biol. 281, 184-95.

Presicce, G.A. \& Yang, X. (1994). Nuclear dynamics of parthenogenesis of bovine oocytes matured in vitro for 20 and 40 hours and activated with combined ethanol and cycloheximide treatment. Mol. Reprod. Dev. 37, 61-8.

Saeki, R., Kato, H., Hosoi, Y., Miyake, M., Utsumi, K. \& Iritani, A. (1991). Early morphological events of in vitro fertilized bovine oocytes with frozen-thawed spermatozoa. Theriogenology 35, 1051-9.

Soloy, E., Kanka, J., Viuff, D., Smith, S.D., Callesen, H. \& Greve, T. (1997). Time course of pronuclear deoxyribonucleic acid synthesis in parthenogenetically activated bovine oocytes. Biol. Reprod. 57, 27-35.

Solter, D. (1988). Differential imprinting and expression of maternal and paternal genomes. Annu. Rev. Genet. 22, 12746.

Stojkovic, M., Büttner, M., Zakhartchenko, V., Brem, G. \& Wolf, E. (1998). A reliable procedure for differential staining of in vitro produced bovine blastocysts: comparison of tissue culture medium 199 and Ménézo's B2 medium. Anim. Reprod. Sci. 50, 1-9.

Susko-Parrish, J.L., Leibfried-Rutledge, M.L., Northey, D.L., Schutzkus, V. \& First, N.L. (1994). Inhibition of protein kinases after an induced calcium transient causes transition of bovine oocytes to embryonic cycles without meiotic completion. Dev. Biol. 166, 729-39.

Suttner, R., Zakhartchenko, V., Stojkovic, P., Müller, S., Alberio, R., Medjugorac, I., Brem, G., Wolf, E. \& Stojkovic, 
M. (2000). Intracytoplasmic sperm injection in bovine: effects of oocyte activation, sperm pretreatment and injection technique. Theriogenology 54, 935-48.

Verlhac, M-H., Cúbica, J.Z., Clarke, H.J. \& Maro, B. (1994). Microtubule and chromatin behavior follow MAP kinase activity by not MPF activity during meiosis in mouse oocytes. Development 120, 1017-25.

Vitullo, A.D. \& Ozil, J-P. (1992). Repetitive calcium stimuli drive meiotic resumption and pronuclear development during mouse oocyte activation. Dev. Biol. 151, 12836.

Webb, M., Howlett, S.K. \& Maro, B. (1986). Parthenogenesis and cytoskeletal organization in ageing mouse eggs. J. Embryol. Exp. Morphol. 95, 131-45.
Wells, D.N., Misica, P.M. \& Tervit, H.R. (1999). Production of cloned calves following nuclear transfer with cultured adult mural granulosa cells. Biol. Reprod. 60, 996-1005.

Xu, K.P. \& Greve, T. (1988). A detailed analysis of early events during in vitro fertilization of bovine follicular oocytes. J. Reprod. Fertil. 82, 127-34.

Yamazaki, W., Ferreira, C.R., Méo, S.C., Leal, C.L.V., Meirelles, F.V. \& Garcia, J.M. (2005). Use of strontium in the activation of bovine oocytes reconstructed by somatic cell nuclear transfer. Zygote 13, 295-302.

Yang, X., Presicce, G.A., Moraghan, L., Jiang, S. \& Foote, R.H. (1994). Synergistic effect of ethanol and cycloheximide on activation of freshly matured bovine oocytes. Theriogenology 41, 395-403. 